\title{
Perception of depth in the profoundly retarded*
}

\author{
ROBERT GARCIA, CHARLES C. CLELAND, WILLIAM RAGO, PAUL WAYNE, and JON D. SWARTZ* \\ University of Texas at Austin, Austin, Texas 78712
}

\begin{abstract}
Profoundly mentally retarded male Ss, having a $\bar{M}$ social age of 1.65 and a $\bar{M}$ social quotient of 6.63 , were tested for depth perception on the "visual cliff" (Gibson \& Walk, 1960). Thirty-nine percent of those tested clearly perceived this illusion of depth. The theoretical and practical implications of this experiment, and further experiments to be carried out in the future, are discussed.
\end{abstract}

It has now been demonstrated that a wide variety of animals can perceive depth as soon as they can move about (Gibson \& Walk, 1960). Chicks and goats have such capacity on the first day of life, rats and cats by 3 to 4 weeks, while depth perception in normal human infants appears to manifest itself between 6 to 10 months (Gibson \& Walk, 1960). Depth discrimination, once locomotion is established, is crucial to species survival.

Walk (1966), in discussing the differing performances between infants younger than 300 days and older than 325 days on the "visual cliff," concludes, "At the moment ... an explanation of the behavior of the infants on the visual cliff would be based on a combination of rate of maturation of visual mechanisms and visual-motor experience [p. 102]." Walk emphasizes the importance of further research in this area by indicating "research on human infants must be carried on further to assess the role of visual-motor experience [p. 106]." In all studies assessing the behavior of species below man in the phyletic order as well as those on human infants, the Ss assumedly all were neurologically intact. Thus, a lacuna exists insofar as the variable of intelligence is concerned; and a search of the literature on depth perception in humans revealed no study in which intelligence was considered in relationship to depth perception. The question raised in the present study is, how will adults, whose mental ages are below 2 years, behave on the visual cliff (VC) (Gibson \& Walk, 1960)? Will their massive cognitive deficit erase their ability to perceive depth?

\section{METHOD}

\section{Subjects}

Initially, 22 Ss were selected for the study; however, due to lack of cooperation, only 18 ambulatory profoundly mentally retarded (PMR) males eventually were employed in the walk condition (WC) and 20 in the crawl condition (CC). In addition, Ss having gross visual and/or auditory impairments were excluded. All Ss were untestable on standardized, individual

*The authors thank Messrs. Harris, Weaver, Robertson, Leverett, Kirk, and Birdsong for their assistance; also, Ms. Caffee and Ms. Campbell and Drs. Hinojosa, Worley, and Lawrence for permission to conduct this study at Travis State School (Texas); and Benjamin F. Fruchter, who takes full editorial responsibility for the contents, for agreeing to sponsor this paper. Reprint requests should be sent to Charles $\mathrm{C}$. Cleland. intelligence tests, but Vineland Social Maturity Scale (Doll, 1947 ) results revealed a $\bar{M}$ social age of 1.65 with a range of 1.12 to 1.94 years. Social quotient (SQ) $\bar{M}$ was 6.63 (range of 5 to 8 ). Chronological age (CA) $\bar{M}$ was 40.16 years (range from 29.9 to 54.3 years). The $\bar{M}$ length of institutionalization was 25.2 years (range from 3 to 48 years). In terms of mental age, these adults closely paralleled the CAs of Gibson and Walk's (1960) normal infant sample (6-14 months).

\section{Apparatus}

The apparatus, except for its larger size, is almost identical to that described in Gibson and Walk's (1960) study. The one employed in this study was a $121.92 \times 243.84 \mathrm{~cm}$ wooden frame into which a $1.27-\mathrm{cm}$-thick Plexiglas of only slightly smaller dimensions was placed. The frame was $45.72 \mathrm{~cm}$ off the floor, and a red and white checkerboard with $5.08-\mathrm{cm}$ squares was attached directly to the underside of exactly half the area of the Plexiglas. The floor area of the other half was also covered with the checkerboard design, and this $45.72-\mathrm{cm}$ difference created an effective illusion of depth. To eliminate sag, a board was installed directly under the center start board. This start board, $2.54 \times 25.40 \mathrm{~cm}$, was similarly covered with the checkerboard design and was directly centered across the $121.92-\mathrm{cm}$ space. The apparatus was pretested to support over $90.718 \mathrm{~kg}$, since the Ss were neither infants nor young animals.

\section{Procedure}

All Ss, unlike Gibson and Walk's infants, were ambulatory. Thus, it was planned that each $S$ be exposed to the VC under both walk and crawl conditions. Each $S$ was led by $E$ to the apparatus and assisted onto the surface in a walking (normal locomotion mode) approach first. The female attendant most familiar to the Ss (8-5 shift and longest tenured) who served as the mother surrogate subsequently beckoned $S$ first to the deep, then to the shallow side. Following this, $E$ repositioned $S$ on the center start board for the crawl approach and the mother surrogate repeated her call from the deep side, then from the shallow. Three Os were inconspicuously positioned to record Ss' reaction time, movement of approach-avoidance, and to make clinical notes. If $S$ failed to respond or was notably oblivious to the VC for $3 \mathrm{~min}$, a judgment of neutral was recorded.

The study was conducted in an unfurnished room $5.4864 \mathrm{x}$ $5.4864 \mathrm{~m}$ on the large, single-story ward housing all Ss. Hospital screens were employed to conceal Os and to assist $\mathrm{E}$ in guiding Ss onto the apparatus. Lighting was directed so that no shadows or reflections detracted from the full illusion of depth.

\section{RESULTS}

Interscorer reliability coefficients were computed, using cosine-pi approximations of tetrachoric rs. A tetrachoric $r$ gives a coefficient that is numerically equivalent to a Pearson $r$ and may be regarded as an 
approximation of it. The two Os positioned on the sides of the apparatus, where it was possible to record Ss' behavior most accurately-since the two screens did not obstruct the view-produced correlations across all conditions ranging from .71 to 1.00 with a mean $\mathrm{r}$ of .88. The third $\mathrm{O}$, whose view was obstructed somewhat, agreed with the other Os less frequently (mean rs of .71 and .74). Consequently, his recordings of Ss' behavior were employed only in the few instances when the other, more reliable Os disagreed on a particular observation.

Table 1 shows the $\mathrm{Ss}^{\prime}$ responses, expressed in percentages, under the two experimental conditions. By inspection, it is evident that the Ss' normal mode of locomotion (walking) yielded a greater number of approach responses. Ss' cooperation in crawling was far less than in walking, and the percent of neutral responses (Ss refusing to move in either direction) consequently more than doubled, as presented in Table 1 .

Of primary interest in the WC results are the seven Ss who moved only to the shallow side of the apparatus, despite the entreaties of the surrogate mother, positioned at the deep end, to come to her. It is certain that this group (39\% of N) clearly perceived and reacted to the VC phenomenon. Moreover, five of these seven Ss had SAs in excess of 1.50 . It can be speculated, of course, that another group of Ss may have perceived the VC phenomenon also-the "neutral" ones who refused to move in the WC condition. Since these Ss would not move off the center board in either direction, however, there is equal likelihood that they did not perceive the VC phenomenon.

Of interest clinically were some of the reactions of the Ss upon noting the "cliff." Quite literally, certain Ss" visual attention to the cliff could best be described as "riveted." $S_{6}$, on noting the apparent deep drop, instantly disregarded the surrogate mother's entreaties, sat down on the center start board, and "held on" with both hands. While so positioned, $\mathrm{S}_{6}$ tested the deep by cautiously inching one foot out into the deep. Although no loss of support occurred, $S_{6}$ was clearly unconvinced, as witnessed by his refusal to leave safety for "mother." $\mathrm{S}_{13}$, on spotting the deep, responded almost identically

Table 1

Percentages of Subjects Exhibiting Each of Three Possible Responses to Each Side of the Visual Cliff Under Two Conditions

\begin{tabular}{|c|c|c|c|c|}
\hline & & $\begin{array}{l}\text { Walk (WC) } \\
(\mathrm{N}=18)\end{array}$ & $\begin{array}{c}\text { Crawl (CC) } \\
(\mathrm{N}=20)\end{array}$ & $\begin{array}{c}\text { Total } \\
\text { (Average } \\
\text { Percent) }\end{array}$ \\
\hline Avoid & $\begin{array}{l}\text { Deep } \\
\text { Shallow }\end{array}$ & $\begin{array}{r}38.8 \\
0.0\end{array}$ & $\begin{array}{l}20.0 \\
15.0\end{array}$ & $\begin{array}{r}29.4 \\
7.5\end{array}$ \\
\hline Neutral & $\begin{array}{l}\text { Deep } \\
\text { Shallow }\end{array}$ & $\begin{array}{l}33.3 \\
33.3\end{array}$ & $\begin{array}{l}70.0 \\
70.0\end{array}$ & $\begin{array}{l}51.6 \\
51.6\end{array}$ \\
\hline Approach & $\begin{array}{l}\text { Deep } \\
\text { Shallow }\end{array}$ & $\begin{array}{l}27.8 \\
66.7\end{array}$ & $\begin{array}{l}10.0 \\
15.0\end{array}$ & $\begin{array}{l}18.9 \\
40.8\end{array}$ \\
\hline Total* & $\begin{array}{l}\text { Deep } \\
\text { Shallow }\end{array}$ & $\begin{array}{r}99.9 \\
100.0 \\
\end{array}$ & $\begin{array}{l}100.0 \\
100.0 \\
\end{array}$ & $\begin{array}{l}99.9 \\
99.9\end{array}$ \\
\hline
\end{tabular}

*Percentages are rounded off to nearest whole number. to $S_{6}$. Others who noted the illusion quite simply froze, and no entreaties by "mother" could budge them. Clearly, once the "cliff" was detected, our depth-sensitive Ss were in a highly attentive state. With one $\mathrm{S}$, once the experimental tasks had been completed, the $\mathrm{E}$ deviated from procedure by crawling over the deep end (and using both an $M \& M$ and social praise from "mother") and trying to teach this observing $S$ that the cliff was a hoax. This demonstration of safety failed to influence this S's willingness to crawl onto the deep end.

In the WC, moreover, not a single $\mathrm{S}$ went only to the deep side. Although there was less cooperation overall, similar results were obtained for the CC. Fifteen percent of the Ss crawled to the shallow side only, while only 5\% (one S) crawled to the deep side only. (A full 70\%, or 14 of $20 \mathrm{Ss}$, refused to move off the center starting board in the CC.) The three Ss who moved to the shallow side only in the CC were spread across the full SA range, while the one $\mathrm{S}$ who moved to the deep side only had a SA of 1.65 .

The four Ss in the WC and one S in the CC who moved to both the deep and shallow sides presented some conceptual confusion until individual protocols were examined. When this was done, it was discovered that three of the four Ss who moved to both sides in the "walk" condition never looked down, while the fourth (and the single S in the CC) was described by all Os as being "oblivious to the cliff."

\section{DISCUSSION}

The present study involving adult humans $(\overline{\mathrm{M}} \mathrm{CA}=40.16)$ with infant mental ages ( $\overline{\mathrm{M}} \mathrm{SA}=1.65$ years) suggests that experience is not an overwhelming influence on depth perception for this rare $\mathrm{S}$ group. Possible neurological impairments in our Ss, however, render comparisons with normal infants difficult. In addition, most of our Ss had been institutionalized over half their lives; hence, visual-motor experiences may be qualitatively and quantitatively different. Nevertheless, $39 \%$ clearly did see the VC phenomenon. Thus, the mechanisms responsible for depth perception have survived the gross retardation in a sizable percentage of our Ss, who, like Walk and Gibson's (1961) infants, were comparable in their reluctance to move to the deep side. Ontogenetically, it is interesting that survival needs, as shown by those Ss who saw danger in the VC situation and adaptively responded to it, appear to precede self-recognition. In an earlier study, ambulatory adult males having SQ $\bar{M} s$ of 12.68 and 10.1 (as contrasted with our current group's ( $\bar{M}$ SQ of only 6.63 ) were unable to recognize themselves after two types of mirror training (Pechacek et al, 1973). Thus, in self-recognition, our Ss are less capable than chimpanzees (Gallop, 1970) and are inferior to infant rhesus monkeys in depth perception (Rosenblum \& Cross, 1963).

Unanswered by this study is the question, "would specific training influence their behavior on the cliff?" Could our Ss, who unquestionably saw the cliff, be trained to go to either side by the E repeatedly demonstrating a safe passage and receiving hugs and M \& Ms at the journey's end? Again, if Walk's (1969) forced method which greatly increased normal infants' depth sensitivity had been employed, would we find more or maybe all our Ss capable of VC perception? In addition, further studies could address the intelligence variable and its influence on VC behaviors by ascending the intellectual ladder to determine at what point in measured intelligence all Ss are capable of perceiving depth. It could also prove valuable to assess VC behavior of PMRs of different etiologic classifications. Again, 
and unknown at present, is the question of the possible role of drugs on VC performance. Since the Ss employed in the present study could not be "lifted from medical orders" and over 50\% were on drugs, would the percent definitely perceiving the VC phenomenon have increased? These and other questions await further study.

While results from this study cannot be generalized to all PMRs, several practical implications can be entertained. For example, those Ss having depth perception, and who adaptively avoided, might be similarly dissuaded if "cliffs" were placed before the entrances of dangerous passageways or off-limits rooms in their dormitories. Should the PMRs learn, through observation, that others successfully crossed the "deep," such could help to classify PMRs into fast vs slow groupings. Were PMRs with depth perception housed in one dormitory, better ventilation could be maintained by open doors and abandonment of one of the attendants' status symbols (keys) could occur. Such might lend an "openness" to wards customarily known as "closed."

MacAndrew and Edgerton (1964) have alluded to the profoundly retarded as constituting a "research backwater," and have indicated why so little research has occurred. Precisely what the outer limits of the PMRs' trainability might be is still largely unknown. In the present study, the extent of depth sensitivity for a small group of PMRs has been determined. Further studies are planned to help map the cognitive, motivational, affective, and learning "terrain" of this rare human group.

\section{REFERENCES}

Doll, E. A. The measurement of social competence: A manual for the Vineland Social Maturity Scale. Minneapolis, Minn: Educational Test Bureau, 1947.

Gallop, G. G. Chimpanzees: Self-recognition. Science, 1970

Gibson, E. J., \& Walk, R. D. The visual cliff. Scientific American, $1960,202,64-71$

MacAndrew, C., \& Edgerton, R. B. The everyday life of institutionalized "idiots." Human Organization, 1964, 23, 312-318.

Pechacek, T. F., Bell, K. F., Cleland, C. C., Baum, C., \& Boyle, M. Self-recognition in profoundly retarded males. Bulletin of the Psychonomic Society, 1973, 1, 328-330

Rosenblum, L. A., \& Cross, H. A. Performance of neonatal monkeys in the visual cliff situation. American Journal of Psychology, 1963, 76, 318-320.

Walk, R. D. The development of depth perception in animal and human infants. Monographs of the Society for Research in Child Development, 1966, 31, 82-108.

Walk, R. D. Two types of depth discrimination by the human infant with five inches of visual depth. Psychonomic Science,
$1969,14,253-254$.

Walk, R. D., \& Gibson, E. J. A comparative and analytical study of visual depth perception. Psychological Monographs, 1961, 75, 1-42.

(Received for publication May 28, 1974.) 